\title{
Amor gay en dos ficciones televisivas argentinas. Entre la reproducción y la contestación de la heteronorma ${ }^{1}$
}

\author{
Gay love in two Argentinean soap operas. Between the \\ reproduction of and the opposition to heteronormativity
}

\author{
Amor gay em duas novelas argentinas. Entre a reprodução e a resposta \\ da heteronormatividade
}

MAXIMILIANO MARENTES, Consejo Nacional de Investigaciones Científicas y Técnicas, Universidad de Buenos Aires, Universidad Nacional de General San Martín, Buenos Aires, Argentina (maximiliano.marentes@hotmail.com)

\section{RESUMEN}

En este artículo se analizan dos historias de amor gay que ocuparon un rol protagónico en dos telenovelas argentinas recientes, Farsantes y Viudas e hijos del Rock $\&$ Roll, y se proponen tres ejes de análisis para pensar la reproducción y la contestación de la heteronorma: hablar de sexo, el final feliz y la intersección entre orientación sexual y clase social. El autor intenta leer estas historias no solo en clave de las matrices genéricas en las que se inscriben, sino también en su relación con una memoria narrativa propia de los relatos sobre homosexualidad.

\section{ABSTRACT}

In this paper, we analyzed two gay love stories that had a leading role in two recent Argentinean soap operas, Farsantes and Viudas e hijos del Rock E Roll. We propose three analysis axes to think about how these stories reproduce and contest heteronormativity: talking about sex, the happy ending and the intersection between sexual orientation and social class. The aim is to read these stories not only in the gender matrix to which of each one belongs to, but also in their relationship with a specific narrative memory typical of stories about homosexuality.

Keywords: gay love; Argentinean soap operas; heteronormativity; telenovela.

\section{RESUMO}

Neste artigo analisamos duas histórias de amor gay que tiveram destaque em duas telenovelas argentinas recentes, Farsantes e Viúas e Hijos del Rock and Roll, e propuseram três eixos analíticos para pensar a reprodução e a contestação da heteronorma: falar de sexo, o final feliz e a intersecção entre orientação sexual e classe social. O autor tenta ler tais histórias não apenas atráves das matrizes de gênero em que se inscrevem, mas também em sua relação com uma memória narrativa própria dos relatos sobre homossexualidade.

Palavras-chave: amor gay; ficções televisivas argentinas; heteronormatividade; telenovela. 


\section{INTRODUCCIÓN: ¿AMORES DIFERENTES?}

Las historias de amor suelen ser los ejes que estructuran las ficciones televisivas. Tradicional y mayoritariamente, estas historias han sido entre un hombre y una mujer, quedando los romances entre personas del mismo sexo relegados a un segundo plano. Entre 2013 y 2015 hubo al menos dos ficciones diarias argentinas, emitidas en canales abiertos, en las que la historia de amor entre dos varones detentaba un lugar central. El surgimiento de estas ficciones puede explicarse por diversos cambios sociales; sin embargo, aunque estas historias de amor implican algunas rupturas con la heteronormatividad, continúan reproduciendo otros de sus rasgos.

A partir del análisis de estas historias de amor, a lo largo del trabajo intento demostrar cómo y de qué manera una de las ficciones tiene una visión más crítica de la heteronorma con base en tres aspectos específicos: el tratamiento de la sexualidad, el desenlace de la historia y la intersección con la clase social. Para lograr el objetivo, recupero aportes de los estudios culturales británicos que incitan a considerar la propia experiencia de los actores; en este caso, una narrativa propia de la homosexualidad. El trabajo se estructura en siete apartados. El primero ofrece una discusión teórica sobre la vinculación entre amor y medios de comunicación. Se continúa con la contextualización de las ficciones analizadas, mientras que el tercer apartado presenta las notas metodológicas. Las secciones cuatro, cinco y seis refieren a los aspectos de las historias que cuestionan la heteronorma: la sexualidad, el final y la relación con la clase social, respectivamente. Finalmente, se entregan las conclusiones del trabajo.

\section{DISCUSIÓN TEÓRICA: PENSAR EL AMOR GAY EN LOS MEDIOS}

La principal característica del amor romántico es la elección individual del sujeto amado (Beck \& BeckGernsheim, 2001; Giddens, 2004; Illouz, 2009, 2012; Jónasdóttir, 2014; Luhman, 2008). Como sostiene Illouz (2012, p. 33), existe un entorno social que orienta las elecciones: la ecología de la elección. Los procesos que conforman dicha ecología son tanto políticas deliberadas como no deliberadas. Un ejemplo de las primeras es la Ley 26.618 de Matrimonio Igualitario, sancionada en Argentina en 2010, que permite que dos personas del mismo sexo se casen, mientras que la incorporación de historias de amor entre personas del mismo sexo en los medios masivos de comunicación es un ejemplo de políticas no deliberadas. Evidentemente, ambos procesos se encuentran imbricados, ya que la mayor presencia de personas gay en medios de comunicación contribuyó a dar legitimidad a los reclamos de esa comunidad (Meccia, 2006).

Cuando Illouz (2009) analiza la relación entre los medios de comunicación y el amor romántico, concluye que los primeros favorecen la constitución de una utopía romántica. Esto la lleva a plantear cuán codificadas están las experiencias románticas, al punto de que los medios masivos de comunicación crean los guiones culturales en los que se enmarcan las experiencias amorosas. La propuesta de Illouz -en la que se encuentran postulados similares a los de la escuela de Frankfurt- deja entrever que lo que emiten los medios de comunicación será recibido y replicado por los consumidores de una manera acrítica y sin mediación. La existencia de una forma de amar real que los medios contaminan con sus historias románticas y ficcionalizadas $^{2}$ es una premisa en su planteo teórico.

Ahora bien, cuando se intenta replicar el análisis para las historias de amor entre varones, la especificidad de la experiencia de la homosexualidad abre interrogantes. Sabiendo que las historias de amor gay en los medios de comunicación son recientemente aceptadas, ¿cómo han amado los varones gay a lo largo de la historia? ¿Oponiendo su amor a la utopía romántica heterosexual o replicando sus guiones culturales? La influencia de la escuela de Frankfurt, que enfatiza la forma en la que se reproduce la alienación cultural, es poco compatible con una postura que intente subrayar los cambios sucedidos en la forma de contar el amor entre varones.

Siguiendo la propuesta epistémica de Illouz (2009), resultaría esperable encontrarse que las historias de amor gay en los medios de comunicación solo reproducen el derrotero amoroso heterosexual. Esta visión es coincidente con las lecturas que sostienen que cuando el matrimonio - una institución reproductora de la heteronormatividad-es entre dos personas del mismo sexo, lo único que haría es reproducir las bases de la heterosexualidad obligatoria. El movimiento gay, cooptado por el régimen heteronormado, perdería así su capacidad crítica ${ }^{3}$.

La visión pesimista de la forma en que son narradas las historias de amor entre varones en los medios masivos de comunicación, incluso luego de la sanción de una ley que "normalizaría" las trayectorias amorosas de los gay, sostendría que esas historias son la mera reproducción de trayectorias diseñadas para 
parejas heterosexuales. Dicho argumento, consistente en algún punto con la visión de la escuela de Frankfurt, puede ser objetado a partir de una de las críticas de Butler (1999) sobre la simple reproducción de los roles de género en parejas del mismo sexo. La filósofa referente de la teoría queer sostiene que, en las parejas de mujeres, butch y femme 4 no serían la copia de un original (varón y mujer en relaciones heterosexuales), sino que, dado que no existe un referente original real al que imitar, butch y femme serían en todo caso la copia de una copia.

$\mathrm{Al}$ aceptar que las historias de amor gay retratadas en los medios no implican una simple reproducción de las figuras que funcionan para contar historias de amor heterosexuales, su análisis requiere ser complementado por otro andamiaje conceptual. El objetivo de este trabajo es comparar dos historias de amor entre varones que fueron centrales en dos telenovelas argentinas recientes (entre 2013 y 2015). La pregunta que guía el trabajo es cuál de las dos historias, enmarcadas en géneros televisivos diferentes, contiene más elementos heteronormativos. Siguiendo a Pecheny (2008), la heteronormatividad es la organizadora "del orden de relaciones sociales, política, institucional y culturalmente reproducido, que hace de la heterosexualidad reproductiva el parámetro desde el cual juzgar (aceptar, condenar) la inmensa variedad de prácticas, identidades y relaciones sexuales, afectivas y amorosas existentes" (p. 14)

Si bien retomo algunos postulados de Mazziotti (1993) y de Aprea y Soto (1998) sobre la importancia del género discursivo en el análisis de las ficciones, intento seguir la premisa de Thompson (1995) y de Williams (1982), exponentes de los estudios culturales británicos, de recuperar la experiencia en la que tienen lugar los acontecimientos. Mi objeto y el del historiador británico - que analizó motines en la Inglaterra del siglo XVII-no tienen prácticamente nada en común, pero al rastrear el sentido que los cambios en las relaciones económicas trajeron para el pueblo, Thompson situaba esas experiencias en su historia particular. Williams, al indagar sobre los sentidos de las nociones de cultura y sociedad, realizó un trabajo similar: reconstruir las experiencias de los autores sobre esos términos. El análisis que propongo de las historias de amor de las ficciones Farsantes y de Viudas e hijas del Rock and Roll es reconocer las especificidades genéricas (novela dramática y telecomedia, respectivamente), pero en la intersección con una narrativa de los relatos sobre homosexualidad. Desde este ángulo, ver cómo se tejen las relaciones de amor entre los protagonistas de las ficciones implica también rastrear marcas propias de las historias de amor entre varones, lo que excede al análisis solamente centrado en los géneros discursivos. Por ejemplo, que una telenovela contemporánea finalice con un casamiento entre los protagonistas es más esperable que que termine con uno de ellos muertos. Se diría, a priori, que la primera reproduce más las normas del género y que la segunda es más rupturista. Ahora bien, como intento demostrar más adelante, esto puede ser cuestionado cuando se piensa en que esos protagonistas son dos varones: en la historia de la homosexualidad, la tragedia era lo habitual y el final feliz, lo contestatario.

\section{CONTEXTUALIZACIÓN DE LAS HISTORIAS DE AMOR}

La ficción televisiva Farsantes, ligada al género de la telenovela -que retoma bastante del melodrama-, es una ficción diaria que, habiendo sufrido cambios de horarios, se emitió luego del horario de protección al menor, las 22.00 horas. Aunque estaba pensada originalmente como una miniserie, debido a cambios en la programación de Canal Trece, devino en una telenovela diaria. Se emitió desde el 26 de junio de 2013 hasta el 12 de febrero de 2014. En 125 episodios de 60 minutos aproximadamente, cuenta las historias de un estudio de abogados penalistas del Gran Buenos Aires. La historia de amor central del programa es la de Guillermo Graziani (Julio Chávez), un muy reconocido abogado penalista de alrededor de cincuenta años, con Pedro Beggio (Benjamín Vicuña), un joven abogado de unos treinta años que se incorpora al estudio como socio en los primeros capítulos. El mayor de los abogados, casado y con un hijo de veinte años, mantiene una vida homosexual paralela a su matrimonio. Su esposa lo sabe y lo acepta. El más joven de los abogados se casa con su pareja ya avanzada la telenovela.

En Viudas e hijas del Rock and Roll (en adelante Viudas...), la historia de amor que analizo es entre Segundo Arostegui (Juan Minujín) y 'Tony' Zoilo (Juan Sorini). Esta telecomedia cuenta con 154 episodios de 60 minutos aproximadamente y se emitió por Telefé, originalmente pasadas las 21.15 horas, aunque sufrió luego cambios de horario, pasando a las 22.15 y finalmente a las 23.00. El primer episodio se emitió el 18 de agosto de 2014 y el último el 13 de mayo de 2015. Segundo, miembro de una familia aristocrática que solo conserva el apellido, es un polista de unos treintaicinco 
años, está casado y tiene dos hijos. Tony es un petisero - quien se encarga de cuidar los caballos- de un poco menos de treinta años que comienza a trabajar para la familia luego de que Segundo lo conociera y quedara deslumbrado por su cuerpo. Segundo tiene intereses en otros hombres, pero siempre luchó contra su homosexualidad. De Tony se sabe que es soltero y viene de una pequeña zona rural de la provincia de Buenos Aires. La historia de amor entre ellos comienza siendo secundaria y va creciendo al punto de que el casamiento del final de la telecomedia fue entre ellos y no entre los dos protagonistas.

En su análisis sobre los estudios culturales en América Latina, Restrepo (2012) recupera la premisa de Grossberg sobre la importancia del contextualismo radical. El autor norteamericano repone la necesidad de contextualizar el fenómeno que se estudia, en este caso dos ficciones televisivas, pero no entendiéndolo como telón de fondo, sino como condición de posibilidad de dicha producción. Sousa Dias (2013) sostenía a los tres meses del inicio de Farsantes que su éxito se debía a un "cambio social". Tanto el matrimonio igualitario como la salida del closet de muchos artistas famosos coadyuvaron a la aceptación y la buena recepción de esta telenovela. Sobre el primero, en julio de 2010 en Argentina se sancionó la Ley de Matrimonio Igualitario que permite se casen dos personas del mismo sexo. Luego de un gran debate parlamentario con movilizaciones políticas bastante agitadas (tanto a favor como en contra), la madrugada del 15 de julio se conocía esta noticia. En otro trabajo sobre una revista de novios gay llamada Amor, atribuí a este acontecimiento el carácter de cronotopo bajtiniano. El concepto de cronotopo es definido como "la correlación esencial de las relaciones espacio-temporales" (Bajtín, 1978a, p. 37, en Arnoux, 2008, p. 63). Si bien Bajtín acuñó esta noción para el análisis de la literatura, puede ser entendida para otros discursos, ya que define una representación de mundo (Arnoux, 2008). El matrimonio igualitario opera como un parteaguas en la historia argentina reciente y su carácter cronotópico también se encuentra en las historias que aquí analizo. En Farsantes se establece cuando Guillermo y Pedro deben atender un divorcio entre dos varones. En Viudas..., con el casamiento de Segundo y Tony. Meccia $(2006,2011)$ reconoce la centralidad que adquirieron los medios para dar cotidianeidad a los vínculos eróticos entre personas del mismo sexo, ayudando a la visibilización y la aceptación de parejas homosexuales. Es por eso que recuperar los estudios culturales adquiere sentido, dado que con ellos es posible observar que, tanto en lo cultural como en lo social, los procesos tienen formas diferentes de materializarse (Cevasco, 2013).

La novedad que implicaron estas dos ficciones diarias es que la historia de amor entre varones sea central en la trama ${ }^{5}$. Debido a mi pregunta de investigación sobre cómo se estructuran las relaciones de amor entre varones, queda para futuras indagaciones un análisis sobre la recepción de estas ficciones. Sin embargo, puedo reconstruir algunos indicios que nos hablen del grado de aceptación y fanatismo que generaron. Guillermo le dice a Pedro, durante una cena en la que hablan sobre amor, que todas las parejas terminan igual (donde igual funciona como sinónimo de mal). Cuando las fanáticas de Farsantes se enteraron de que Pedro moriría, comenzaron una serie de campañas públicas pidiéndole a los autores que no mataran a Pedro, que lo revivieran o que hicieran una segunda parte de la telenovela en la que Guillermo y Pedro pudieran vivir juntos y felices. La frase que acompañaba esas campañas era No todas las parejas terminan igual. Incluso realizaron una protesta fuera de la productora para pedir por la vida de Pedro. Una de las guionistas de la serie, Carolina Aguirre, a dos años del capítulo en el que muere Pedro Beggio, escribió una carta en la que relataba la tristeza que le generó haber matado al personaje y contó que recibió mensajes de reclamo de fanáticas, tanto en los aniversarios de la muerte de Pedro como en el del final de Farsantes (Aguirre, 2015). También la guionista menciona el fan-fiction creado alrededor de estos dos personajes.

La historia de amor entre Segundo y Tony alcanzó éxito, aunque sin tanta repercusión. El amor del público hacia esta pareja se observa en el sitio web de Telefé. En este, existen decenas de escenas destacadas de toda la telecomedia. A medida que avanzaba, se destinaban más escenas a su historia de amor. En la página de Internet del canal hay tres bonus track con pequeñas escenas de algunos personajes, para las que Segundo y Tony hicieron una sesión de fotos hot. Con todo, reconociendo las limitaciones de no abordar la recepción, el trabajo a partir del texto permite reconocer dilemas sobre las historias de amor entre varones.

\section{NOTAS METODOLÓGICAS: EL AMOR A PARTIR DE ESCENAS}

Mi primer contacto con ambas ficciones fue como espectador de la totalidad de los capítulos cuando las telenovelas se emitieron en sus respectivos canales. Luego, con motivo de mi tesis de maestría, decidí 
incorporarlas al corpus del material a analizar. Debido a la gran cantidad de capítulos y a que mi corpus para la tesis contiene otras historias, trabajo con las escenas destacadas de ambas ficciones, disponibles en los sitios web de los canales. Cuando fue necesario, por cuestiones fundamentales de la trama amorosa, analicé escenas de capítulos que no se encontraban entre los momentos destacados. Por límites espaciales, en este trabajo se recurre a las escenas que mejor muestran los puntos de análisis que desarrollo a lo largo del texto.

El trabajo con el material comenzó con la transcripción de las escenas, en una especie de descripción densa (Geertz, 2003), con resúmenes, notas, comentarios, que me llevaba de uno a otro capítulo. Luego reconstruí las escenas de cada una de las historias, basándome en la metodología de las escenas (Paiva, 2006). A cada una de estas escenas les puse un título que condensara su espíritu en la historia de amor entre los varones.

Como mi unidad de análisis son las historias de amor, y no la totalidad de las ficciones, me concentro en los elementos que ayudan a entender a estas historias en el clivaje reproducción-contestación de la heteronorma. El foco en el contenido de las historias permite ver cómo, desde las mismas historias contadas, son traccionados aspectos críticos de la heteronormatividad a partir de la recuperación de una narrativa de la homosexualidad. Si bien estos elementos no agotan el clivaje analizado, sí aportan -desde un análisis centrado en las historias de amor- interrogantes a la hora de pensar cómo el amor gay es incorporado en las ficciones.

Basado en postulados teóricos, me centro en tres ejes. El primero tiene que ver con cómo cada historia procesa el tema de la sexualidad. Como sostiene Illouz (2012), la sexualidad es uno de los puntos centrales de la forma en la que se organiza e institucionaliza la imaginación romántica. En esa línea, la forma en la que la sexualidad gay aparezca en cada una de las historias permite ver que, cuando se la oculta, deviene un tema sobre el que no es necesario hablar, ya que corresponde al ámbito de lo privado. Ese silencio es coincidente con las políticas de reconocimiento de la homosexualidad conservadoras que analiza Meccia (2011).

El segundo eje responde al final de la historia. Debido al carácter trágico que ha acompañado al amor entre varones a lo largo de la historia, tanto en las biografías como en las ficciones literarias (Melo, 2005), el final feliz con su respectivo casamiento adquiere un matiz diferente, incluso disruptivo, para las historias gay. Así, el matrimonio igualitario se reactualiza, permitiendo salir, como veremos, del heterocentrismo en la forma en la que se ha procesado la diversidad sexual en las producciones culturales a lo largo de la historia.

Por último, el tercer eje se relaciona con uno de los límites de la libertad del sujeto amado en la matriz del amor romántico: la diferencia de clases. Tal como demuestran los estudios centrados en los orígenes socioeconómicos de las parejas heterosexuales (Bericat, 2014; Gómez Rojas, 2007; Illouz, 2012), las personas forman parejas con sus pares de clase social. La utopía romántica (Illouz, 2009) tiende a explotar ese ideario de libertad de formar pareja con otra persona de una clase social muy diferente. Ahora, cuando se reconoce que el estigma de la homosexualidad ha servido para unir a personas de sectores socioeconómicos muy diversos (Pecheny, 2003), el amor entre un patrón de estancia y su empleado rural reactualiza elementos de la historia de esa homosexualidad. Comencemos, entonces, con el primero de los ejes.

\section{HABLAR DE SEXUALIDAD GAY ENTRE EL COMPLETO SILENCIO Y LA HUMORADA}

Un aspecto fundamental en las ficciones románticas televisivas resulta el contacto íntimo entre los protagonistas. Es por eso que el primer beso es tan esperado cuando la historia reactualiza la matriz romántica entre dos amantes que no debieran amarse. El beso, visto como una de las formas más explícitas de la sexualidad (Le Breton, 1999), marca una especie de punto de no retorno: la relación afectiva deriva en otro tipo de vínculo. Eso es lo que les pasa a Guillermo y Pedro el día en que el primero va a cuidarlo porque el otro se enfermó la lluviosa noche anterior cuando fue corriendo a la casa de su socio. Guillermo, recostado junto a un Pedro dormido en su cama, lee el expediente del caso que deben preparar. Pedro se acomoda en la cama, volteándose, como antecediendo su despertar. Antes apoya su cabeza en el brazo de Guillermo, que al haber sentido el más mínimo movimiento le clava la mirada. Pedro abre los ojos y ve que su socio sigue leyendo el expediente. Levanta apenas la cabeza, y su socio le devuelve la mirada, inclinándose levemente hacia abajo. Guillermo se queda inmóvil, esperando que Pedro avance. Este se incorpora en la cama y llega a la altura de su socio. Pedro comienza a besarlo y Guillermo responde continuando con ese, el primer beso. En un tierno gesto, el mayor de los abogados apoya su mano en la mejilla del más joven, antes de moverse un poco hacia atrás. Con una enamorada sonrisa, Guillermo le acaricia la cabeza a Pedro quien, con su 
mirada perdida, le sostiene la mano y se apoya en su pecho. El joven abogado luego se agarrara la cabeza y se preocupa por su mujer y su hijo, mientras que el otro dice que nada había pasado. Para Pedro, el beso es un error. Unos días después, cuando un abogado de otro estudio galantea con Guillermo, Pedro estalla en celos y descuida sus tareas. La discusión alcanza su punto máximo cuando Pedro le pide a su socio no ser básicos y no mezclar las cosas. Un enojado Guillermo responde a gritos que no es básico y que las cosas ya están mezcladas.

Con varios devenires en el ínterin, Guillermo y Pedro tienen su escena de sexo. Pedro reside momentáneamente en una cabaña en el Delta del Río Paraná ${ }^{\text {, donde }}$ está recluido y escondido de la justicia que lo busca por el asesinato de su suegro. Rodeado de velas, ya que no hay luz eléctrica, está acostado. Tocan la puerta y cuando la abre se encuentra con una sorpresa: Guillermo lo fue a visitar. Luego de quejarse por lo difícil que fue llegar hasta allí, ya dentro de la casa comienzan a besarse apasionadamente. Entre besos, abrazos y caricias, Guillermo le va quitando la camisa a Pedro. La noche ilumina de amor la casa y a la toma siguiente, ya es de día. Se reconstruye elípticamente lo sucedido a partir de ciertos signos que indican la escena de sexo: el reencuentro, las velas, la noche y la desnudez de los torsos. A lo largo de la telenovela, este es uno de los pocos contactos sexuales entre Pedro y Guillermo, en una escena de sexo elíptico. Tampoco hay menciones ni comentarios sexuales al respecto. ¿Se debe esto solamente a que Farsantes se emparenta con el melodrama? Sobre esta pregunta, retomo pronto el tema.

Segundo y Tony, en Viudas..., tienen su primer beso a poco de comenzar la telecomedia. Dentro del casco de la estancia, en un sillón junto a un ventanal, Tony consuela a Segundo, quien llora la muerte de su yegua. El patrón, entre llantos, le dice que la va a extrañar, mientras el petisero intenta calmarlo. Segundo comienza a agarrarle el cuello, como para quedar cara a cara y hablarle. Continúa desconsolado mientras le acaricia las mejillas a Tony, quien permanece junto a su patrón. Segundo y Tony se besan por unos tres o cuatro segundos. Si bien parece que el petisero hubiera querido besarlo, luego aparta a su patrón, tomándolo por la cintura. Se miran por un segundo, Tony se levanta y sale corriendo. Absorto ante toda la situación, Segundo permanece sentado en el sillón con la mirada perdida.

Un nuevo beso entre ambos se da unos meses más adelante. Cuando Segundo le confirma al petisero que habló con su hermano y su cuñada, por lo que no lo despedirían de la estancia, Tony se tira hacia Segundo lleno de alegría y comienza a besarlo. El otro responde del mismo modo y siguen besándose, acercándose a un árbol. Luego de esta demostración de amor, el petisero le confiesa a su patrón que no quería "esto". Segundo responde que él tampoco. "No está bien, Don Segundo. Esto no está bien. Usted tiene su familia. Está la señora Miranda que siempre ha sido tan buena gente conmigo. Yo le tengo mucho aprecio". Segundo responde: "No, no, no mezclemos las cosas Tony. No hay que mezclar las cosas". Y Tony agrega mirando a su patrón: "A mí me parece que ya están mezcladas, ¿no? Creo”. Un consternado Segundo le pregunta a Tony, pero a modo de pregunta retórica, "¿Qué hacemos con esto?" (Ortega \& Cullel, 2014-2015).

Además de estos besos, toda la relación entre Tony y Segundo está signada por el deseo sexual explícito. De hecho, el día que se conocieron, Segundo tiene el primero de varios actos fallidos y le dice que está buscando un caño, cuando en realidad lo que busca es un baño. O cuando Tony le pide a Segundo que le enseñe a bailar, este le promete que le enseñará el Teto7: "vos te agachás y yo después te explico", le dice Segundo. En un momento en que el padre de Segundo le apunta con una escopeta y Tony está parado detrás de él, Segundo pide, tanto a su padre como al petisero, que le bajen el fierro ${ }^{8}$ (Ortega \& Cullel, 2014-2015).

En el spa de un hotel en el que pasan el día, Tony le comenta a su patrón que hay otra cosa que quiere decirle: el deseo de dormir y amanecer juntos. Segundo comienza a formular preguntas a medida que Tony va asintiendo: "¿En el hotel? ¿Vos decís en una cama? ¿Cucharita? ¿Vos atrás? ¿Sí, en la cucharita?”. Tony responde complacientemente que donde fuera más conveniente. Segundo sale de la conmoción y, sobresaltado, le da una cachetada a Tony, diciéndole que pare un poco, para convencerse de que no es real (Ortega \& Cullel, 2014-2015). Cachetadas, palmadas y suaves puñetazos son una especie de eufemismo afectivo, es decir, la forma de expresar un contacto íntimo y de aproximarse al cuerpo del otro, disimulando la verdadera intención: establecer un lazo erótico-afectivo. Debido a que las demostraciones de contacto físico entre varones son asociadas a una carencia de virilidad, los gestos de camaradería entre varones, signados por contactos violentos, suelen ser la forma en la que se transmiten otros intereses.

Volviendo a la pregunta que quedó planteada líneas más arriba, ia qué responde que en Farsantes la sexualidad esté silenciada mientras que en Viudas... 
esté más ridiculizada? Tal como sostienen Aprea y Soto (1998), la telenovela suele ser más conservadora y refractaria con los temas controversiales, aprovechando así la telecomedia el registro humorístico para poner en escena esos temas tabúes. De ser así, resultaría que la respuesta se relaciona con los requerimientos genéricos. Como sostuvo una de las guionistas de la telenovela de abogados, "Farsantes es, ante todo, una historia de amor. Segundo, una historia gay" (Sousa Dias, 2013), por lo que el componente amoroso en esta telenovela pesaría más que aquel gay. Ahora, esta explicación debe articulársela con aquella elaborada por McRobbie (1998) sobre las revistas femeninas de los noventa, en la que por medio del humor se hablaba más abiertamente sobre el sexo. El humor sería la clave de explicación sobre este riesgo mayor en Viudas... que en Farsantes.

Si bien estas explicaciones son necesarias, no las considero suficientes para entender porqué una ficción incorpora más elementos que contesten a la heteronorma mientras que la otra no. Como afirmaba la coautora de Farsantes, el amor pesaría más que lo gay. Volviendo a la vida gay, existen posiciones sobre la mayor sexualización de los vínculos entre varones. Uno de esos debates se relaciona con la afirmación de Giddens (2004) sobre la mayor promiscuidad de los gay. Illouz (2012) sostiene -indirectamente sobre los varones gay- que parte de porqué duele el amor radica en que las mujeres, en los últimos tiempos, comenzaron a vivir una sexualidad similar a la de los varones, que priorizan la cantidad de encuentros desligándolos del carácter afectivo. Considero que la hipersexualización es una de las características del mundo gay, muy presente, mediada por el humor en la telecomedia, en el vínculo entre Segundo y Tony. Por lo tanto, priorizar lo romántico por sobre lo gay, sumado a la matriz genérica de telenovela en la que se inscribe, permite entender mejor lo reproductor de lo heteronormativo de Farsantes. El silencio en torno a la sexualidad de los protagonistas de la historia de amor es congruente con la forma conservadora de procesar la homosexualidad: es un tema de la intimidad de las personas (Sullivan, 1996; Meccia, 2011). Ahora, incluso cuando se apela al humor para hablar sobre sexo, la historia de amor de Viudas... reactualiza elementos propios de la experiencia gay, como la hipersexualización, que promueven una aceptación de la homosexualidad sin renunciar a una de sus especificidades. Ahora, ise traduce esto de principio a fin en las historias de amor? El siguiente apartado se centra en los finales.

\section{EL FINAL FELIZ CONTESTATARIO}

Pedro es buscado por la policía por el asesinato de su suegro, una trampa tendida a Guillermo por su medio hermano. El joven abogado se esconde unos días en una casa en el Delta hasta que tiene que volver a la ciudad porque su escondite fue descubierto. Va a su casa a buscar ropa y despedirse de Camila, su mujer, quien lo asesina de un disparo. Esta telenovela no tiene el final feliz que marca a estos discursos en su modalidad actual, sino que un final trágico ${ }^{9}$. Una destrozada e iracunda Camila, quien mendiga el amor de Pedro, termina matándolo cuando él le confirma que se irá con Guillermo.

La historia entre Segundo y Tony tiene el final feliz esperado en las historias de amor de las ficciones televisivas: el casamiento. El día del casamiento, cuando llega a la estancia donde tendrá lugar la ceremonia, un ya preparado Segundo se encuentra con que Tony sigue con ropa de trabajo. Luego de apurarlo, le pide que se tape los ojos: "No me tenés que ver. El novio no tiene que ver a la, al, al otro novio". Tony quita las manos de su rostro y lo espía, y Segundo le da una cachetada. "De verdad Tony. En serio. Es importante. Es importante. Yo soy muy supersticioso. Tocate. Tocate. Tocate todo". Como Tony no entiende para qué se tiene que tocar, Segundo aprovecha y le toca la zona genital al petisero, explicándole que es para que no les dé mala suerte (Ortega \& Cullel, 2014-2015).

Al momento de celebrarse la ceremonia delante de la jueza, Segundo da un discurso en el que no reconoce haber estado en el closet, ya que su vida anterior con Miranda, su ex mujer, siempre fue muy feliz. "De donde sí salí fue de mi cabeza, que no me permitía disfrutar de esto, vivir esto, libremente. Pero ahora así, estoy libre para comerme este chongazo"10, concluye Segundo ante los aplausos y la risa del público. Un tímido Tony solo puede decir "lo amo". La boda se ve momentáneamente interrumpida por la aparición de los padres de Segundo, quienes no fueron invitados al festejo debido a su comportamiento homófobo. Luego de que algunos de los invitados los echen a patadas, se reanuda la ceremonia. El doble sentido sexual sigue operando incluso cuando cambian los anillos: Segundo, aludiendo al tamaño de los dedos de Tony, Tony confesando de manera cómplice al público que finalmente le entró el anillo a Segundo. Luego, se van cabalgando juntos, para comenzar su luna de miel (Ortega \& Cullel, 2014-2015).

Más allá de la diferencia en los finales, a la que volveré, es necesario destacar algunos actantes similares 
y parecidos en ambas historias, que se inscriben en la matriz melodramática (Mazziotti, 1993), de la que la telenovela y la telecomedia toman bastante. Las mujeres de los protagonistas: Ana (Guillermo), Camila (Pedro) y Miranda (Segundo). Ana es una alcohólica que acepta las andanzas homosexuales de su marido y aguanta su doble vida. Camila, quien descubre la sexualidad de Pedro al mismo tiempo que él, no lo tolera y, luego de ofrecerle un pacto de doble vida, termina matándolo. En cambio, cuando finalmente Segundo se lo confiesa a Miranda, esta lo acompaña como amiga y madrina de su casamiento con Tony. El drama marca a las mujeres de los protagonistas de Farsantes, mientras que la libertad y la aceptación a la de la telecomedia.

Otro actante similar en esta historia es el hermano varón de Guillermo (Miguel) y uno de los hermanos de Segundo (Nacho). Miguel está enojado con su medio hermano no solo por su homosexualidad, sino también porque lo culpa por la muerte de su hijo. Nacho, que constantemente acosa a su hermano por ser gay y lo acusa de no atender sexualmente a su esposa, presiona a Segundo porque él no contribuye a resolver la mala situación financiera familiar que la pésima administración de Nacho produjo. En ambas historias, son los hermanos quienes primero reconocen los intereses eróticos de Guillermo y Segundo por Pedro y por Tony, respectivamente. Por compartir un código de hombría común, reconocen en sus familiares cuando estos corren peligro. ¿Será por eso que los hermanos son los villanos de estas historias?

En las ficciones románticas televisivas constantemente aparecen terceros en discordia y muchas veces la historia se teje sobre un triángulo amoroso. Una verdadera amenaza para Pedro es la aparición de Matías, otro abogado que coquetea con Guillermo. Un abogado es también el que trae celos en la historia de Segundo y Tony: el petisero se siente desplazado momentáneamente por el abogado de Segundo, que lo hace cambiar y comienza a actuar de un modo tal que no es el mismo patrón del que se enamoró. Dos representantes de profesiones liberales son los terceros en discordia y los que amenazan el núcleo amoroso de los protagonistas, una premisa del amor romántico (Illouz, 2009).

Los actantes que señalé -ex esposas sufrientes y dejadas o amigas y compañeras, hermanos villanos y abogados terceros en discordia-se tejen de manera tal en la trama que orientan el sentido de esta hacia un lado o el otro. En Farsantes, el drama es incuestionable cuando una despechada ex mujer no acepta el amor de su esposo por otro hombre. Este final trágico contrasta con aquel feliz de Viudas..., en el que el chiste de doble sentido acompaña hasta consumada la boda. ¿Podría concebirse, en términos de ficción televisiva, como más novedoso y rupturista el primer final, mientras que el otro es más naïve y reproductor? Pensarlos en estos términos implica caer, valiéndome de la propuesta de Grignon y Passeron (1989), en heterocentrismo. Estos autores son críticos de Bourdieu, ya que no logra ver la positividad del gusto de los sectores populares y lo caracteriza como gusto de necesidad. Grignon y Passeron sostienen, entonces, que para ver la especificidad y la agencia en las clases menos favorecidas, hay que derribar el dominocrentrismo, es decir, dejar de utilizar como vara para medir la realidad aquella de los sectores dominantes. Aquí intento hacer lo propio, pero cambiando la fuente de dominación: en línea con Connell (2005), la homosexualidad subordinada a la heterosexualidad.

Para continuar con la propuesta de los críticos de Bourdieu, propongo nuevamente pensar en la experiencia de las historias homosexuales en su propia especificidad histórica, para no caer en el heterocentrismo: juzgar con criterios utilizados mayoritariamente para evaluar historias de amor heterosexuales en las ficciones televisivas cuando la pareja es entre dos varones. Melo (2005), en su libro sobre literatura y homosexualidad, dedica una buena primera parte a la tragedia como forma de contar las historias de amor entre varones. Esto no solo como una fórmula de representación de varias épocas, sino también por haber sido este tipo de experiencias a las que fueron expuestas los homosexuales que escribían sus historias de amor. A tal punto que Forster (2003) decide darle un final feliz a Maurice, una historia de amor entre varones, para que por lo menos en el plano ficcional ese romance termine bien. De allí que la matriz trágica de Farsantes sirve más como reproductora de un orden que excluye a las parejas del mismo sexo, ya que la misma historia termina reproduciendo el trágico desenlace que ha caracterizado "al amor de los muchachos" (Melo, 2005, p. 14). En cambio, cuando recuperamos las experiencias de la narrativa de la homosexualidad, el final feliz signado por el casamiento entre Segundo y Tony, que podría ser juzgado como más naïve y normalizador, puede ser entendido como rupturista con el heterocentrismo. Tal como sostiene Fassin (2011), los matrimonios entre personas del mismo sexo siempre son contestatarios en términos políticos. Pero, ¿qué sucede cuando la lógica clasista prima por sobre la de género? Ese será el tema del siguiente apartado. 


\section{AMOR Y CLASES SOCIALES: CRITICANDO LA HOMOGAMIA NORMATIVA}

A pesar de la libre elección del sujeto amado que supone el amor romántico, como respuesta al amor cortés, las parejas suelen conformarse homogámicamente en términos de clases (Illouz, 2009). Muchas telenovelas han tendido a cuestionar esa máxima a partir de la típica historia de una joven de sectores populares que se enamora correspondidamente de un galán de clase alta como, por ejemplo, algunas de las telenovelas protagonizadas por la cantante mexicana Thalía. Sin embargo, la historia de la homosexualidad brinda pistas para criticar estos supuestos.

Tanto Guillermo como Pedro son profesionales de un sector socioeconómico bien posicionado: son abogados. Representantes de las clases medias-altas, tanto por su nivel educativo como por su estilo de vida, desde el comienzo su vínculo está signado por la igualdad. Significante en este tipo de vínculo resulta que varias veces a lo largo de la telenovela estrecharon sus manos en carácter de socios, como cuando Guillermo decide que Pedro vuelva a trabajar en el estudio. Este gesto es símbolo de la relación que mantienen, entre iguales en términos de clases. Claro que esta igualdad es relativa, debido a la amplia trayectoria de Guillermo en el campo penal, que es uno de los motivos que lleva a Pedro a incorporarse al estudio, para aprender del mejor. No obstante, ese ingreso se da en carácter de socio, con una repartición en partes iguales de las causas penales.

Segundo y Tony también comienzan a involucrarse afectivamente a partir del trabajo, pero -a diferencia de la pareja anterior-la brecha de clase es marcada, reforzada y ridiculizada a lo largo de la historia. Segundo proviene de una familia aristocrática, Arostegui, que conserva vastos capitales sociales y culturales, más que económicos. De hecho, para salvar las finanzas de la familia, que fue dilapidada tanto por el padre de Segundo como por su hermano Nacho, los Arostegui pretenden que Segundo recomponga su relación con Miranda, reciente heredera de una radio de rock. Los miembros de esta familia son conocidos jugadores de polo, deporte típico de la aristocracia argentina. Segundo contrata a Tony como petisero al enterarse de que solo hizo un reemplazo en el trabajo anterior, que consistió en llevarle una caballada a su estancia, por lo que no volvería a llevarle más caballos. Tony es un peón rural, tímido y muy agradecido, y sus capitales eróticos parecen no importarle demasiado. El día de spa que comparten en un hotel de lujo, el petisero le agradece a su patrón, porque nunca estuvo en un lugar así.
Que la relación entre ellos esté inscrita en un vínculo laboral no exime que esté basada en una asimetría de posiciones de clase. La continuidad de Tony en la estancia peligra varias veces, sobre todo a pedido del hermano de Segundo. A diferencia de Guillermo y Pedro, su vínculo no es entre socios, sino que es una relación salarial, marcada todavía por resabios de un vínculo señorial. A lo largo de la serie, Tony llama a Segundo por el apelativo patrón. Esta impronta paternalista en el vínculo laboral se traduce también al ámbito amoroso. Segundo, mientras atraviesa su separación con Miranda, tras haberse ido de la casa llevándose a los hijos de ambos, le explica a Tony que lo único que lo hace sonreír últimamente son las fotos que se sacaron en una cabina en el parque de diversiones, donde se divirtieron mucho. Agarrándole el mentón a Tony y hablándole en tono paternal, Segundo le dice que era como un niño. El paternalismo de clase implicaba, al menos en este caso, la infantilización del otro.

La desigualdad entre ambos, además, tiene su correlato en la forma de hablar. Segundo, debido a su posición de clase, maneja a la perfección el inglés, lengua que utiliza de manera cotidiana en su vida, por lo que Tony a veces se confunde. Es tal la identificación con ese idioma que muchos lo llaman Second. Tony, por su parte, desconoce algunos de los términos que utiliza Segundo, tanto en inglés como en español. Su forma de hablar está marcada por la incorrecta pronunciación de algunos fonemas: él no aceptó a Segundo por esposo, sino que lo "acectó".

Habiendo marcado las posiciones de clases de unos y otros protagonistas de estas historias de amor, ¿cuál podríamos pensar que contiene elementos más críticos a la heteronorma? Siguiendo la máxima de recuperar la experiencia de la práctica, es necesario rastrear en la historia de la homosexualidad la vinculación con las clases. Melo (2005) recupera muchas de las historias de varones burgueses que se enamoraron de otros de sectores populares. Pecheny (2003), al analizar las identidades discretas, sostiene que debido a la discreción en el ejercicio de la clandestinidad, eran frecuentes las relaciones entre clases en la sociabilidad gay. De hecho, muchos de los entrevistados de Meccia (2011) concuerdan al recordar que en los lugares de levante y yiro típico de los ochenta y, en menor medida, de los noventa, los baños de distintos lugares que oficiaban de teteras ${ }^{11}$, se establecían vínculos entre representantes de distintas clases sociales. Meccia (2011) sostiene que el pasaje al régimen de la gaycidad implica una mayor apertura de espacios de sociabilidad y encuentro entre varones gay, acompañado 
de una mayor tolerancia. En este nuevo escenario proliferan los lugares que distinguen entre clases sociales, dado que existen reductos para hombres gay de diferentes estratos socioeconómicos, con diferentes gustos y estilos de vida, al mismo tiempo que emergen los lugares friendly, produciendo una suerte de desghettización. Pareciera ser, según este autor, que el nuevo milenio encuentra a los gay más aceptados socialmente, habiendo producido un cambio en la sociabilidad gay. A saber, si antes la experiencia de la homosexualidad aunaba en detrimento de las desigualdades socioeconómicas, ahora en el interior del ambiente gay se refuerzan aquellas inequidades, quedando relegada la diversidad sexual a un segundo plano.

Es por eso que la relación entre Guillermo y Pedro se inscribe más en el escenario de la gaycidad, en el que por momentos la experiencia gay queda relegada a un segundo plano, como si ya no importara. Tal como señalaba la guionista de Farsantes, primero era una historia de amor y, luego, una historia gay. O en palabras de Hall (2004), esta es la forma en que el signo se cruza con las estructuras de la cultura para tomar una dimensión ideológica: la reproducción del heterocentrismo. Si bien la diferencia de clases entre Segundo y Tony pueda ser pensada como más clásica en términos de la narrativa de telenovelas, también debe inscribírsela en una narrativa de la homosexualidad, en la que el contacto y la conformación de parejas heterogámicas en términos de clases sociales, suponen un cuestionamiento a la heteronormatividad que asimiló a la homosexualidad a su imagen y semejanza. Por lo tanto, que dos hombres de estratos socioeconómicos tan dispares acaben casados, no puede ser entendido como la simple reproducción de la utopía romántica (Illouz, 2009), al igual que pasa en las parejas heterosexuales. Por el contrario, debe ser inscrito en la propia experiencia de parejas de varones que, por situarse al margen del régimen heteronormado, desafiaban las fronteras de clases en la conformación de vínculos eróticos-afectivos.

\section{CONCLUSIÓN: "LAS COSAS YA ESTÁN MEZCLADAS”}

A lo largo del trabajo, intenté demostrar cómo Farsantes, acorde con sus pretensiones, desplazó el componente homoerótico a un segundo plano, logrando ser antes que nada una historia de amor. La historia de amor de Viudas..., en cambio, incorporó en su registro humorístico elementos críticos al orden heteronormativo, recuperando tópicos recurrentes en la narrativa gay. No pretendo sostener que esta contestación resulte revolucionaria, pero sí al menos más crítica, tanto en su forma como en contenido, a la aceptación del amor entre varones que implica el borramiento de la propia experiencia gay en tres ejes.

El primero de los ejes se relaciona con las menciones explícitas en torno a la sexualidad. Acorde con discursos que tratan de situar la orientación sexual como una mera cuestión que concierne a la privacidad e intimidad de los involucrados (Meccia, 2011), la historia de amor entre Pedro y Guillermo en Farsantes opta por silenciar el sexo, que -al fin y al cabo-es la fuente de estigma de los gay (Goffman, 2006; Meccia, 2006). Por medio de chistes, Tony y Segundo, en Viudas... no solo hacen comentarios que aluden a su sexualidad, sino que también recuperan con humor uno de los puntos de la experiencia de la homosexualidad: su hipersexualización.

Cómo terminan las historias es otro de los ejes de análisis. Mientras la tragedia signa el final de la historia de amor entre varones de Farsantes, la de Viudas... concluye con una boda. Como se dijo, el novio asesinado es un recurso más original para las telenovelas contemporáneas, no obstante lo cual termina reactualizando una de las máximas de la heteronormatividad: dos varones que se aman no pueden terminar ni juntos ni bien. La tragedia ha sido una de las marcas de las historias de amor entre varones, tanto en la literatura como en las biografías, por lo que el final feliz marcado por la boda -el recurso más trillado para las parejas heterosexuales en las telenovelas- debe ser entendido en dicha especificidad.

La diferencia de clase entre los protagonistas de las historias de amor es el tercer eje que analizo. La libertad individual de elegir con quién formar una pareja encuentra límites en términos de las clases sociales. Por eso, la historia de Guillermo y Pedro en Farsantes es más acorde con una nueva forma de procesar la diversidad sexual: subsumiéndola en la desigualdad de clases. En la historia de la homosexualidad, y hasta hace no mucho tiempo, la diversidad sexual primaba por sobre la diferencia de clases, logrando que se generaran contactos entre personas de estratos socioeconómicos muy diversos (Meccia, 2006; Melo, 2005; Pecheny, 2003). De allí que la unión entre un estanciero y un patrón, estilizada por el medio televisivo, continúa trayendo un elemento de resistencia a la forma en que actualmente la heteronormatividad procesa la diversidad sexual. A saber, eliminando lo específicamente gay. Por eso, 
con todo, el melodrama Farsantes aplica, recuperando el concepto de McRobbie (2010) una suerte de mascarada postigualitaria, en la que se niega lo diferente de la homosexualidad.

Fuente de inspiración resultaron los estudios culturales británicos debido a una de sus preguntas desde sus orígenes: la pregunta por el cambio. Las transformaciones en la sociedad con respecto a la mayor aceptación de la homosexualidad permiten pensar sus diálogos con la producción cultural, como las dos telenovelas analizadas aquí, ayudando a modificar la ecología de la elección (Illouz, 2012) y dando visibilidad al amor entre varones (Meccia, 2006). Recuperando, por medio de Williams (2009), la premisa de Voloshinov sobre el signo, las producciones culturales no solo reflejan, sino que también refractan, la sociedad.
"Las cosas ya están mezcladas" es la frase de los protagonistas de las historias de amor cuando hacen referencia a sus romances. Por último, quisiera recuperar esa frase, pero en otro sentido. El amor entre personas del mismo sexo no es una prerrogativa de estas telenovelas, sino que ya ha habido cientos de ficciones que las retoman, con más o menos naturalidad. La novedad aquí consistió en el carácter protagónico de estos romances, en ficciones diarias en canales abiertos. Sin embargo, tal como viene sucediendo, es dable arriesgar que el amor entre muchachos conviva sin tantos inconvenientes al lado del amor entre varones y mujeres, pero otras formas de amor (como entre dos mujeres, entre travestis, transgéneros y transexuales, vínculos poliamorosos, entre otros) continúen sin mezclarse tanto en las diferentes tramas.

NOTAS

1. Agradezco los valiosos comentarios de Libertad Borda y Sergio Caggiano a una versión previa de este texto. Asimismo, las sugerencias de quienes evaluaron el artículo han contribuido a mejorarlo enormemente. Mi agradecimiento es extensivo al equipo editorial de la revista por sus precisas correcciones de estilo.

2. Esa forma de ver el amor es consecuente con la literatura que ve en los medios de comunicación solamente la reproducción de los roles de género a partir de la codificación de ciertos estereotipos (Wood, 1994). Una lectura opuesta es sugerida por Weitman (1999), quien analiza el erotismo en revistas, dado que que allí se encontraría en estado puro, sin contaminación.

3. Para una crítica a estos argumentos, véase Hiller (2012, 2013) y Jones y Hiller (2015).

4. Con estos términos, se designa en inglés a lesbianas más masculinizadas y más feminizadas, respectivamente. Opto por los términos en inglés para que no se generen confusiones al traducirlos al castellano rioplatense.

5. En Los Roldán, una ficción diaria argentina emitida entre 2004 y 2005, cobra mucho protagonismo la relación entre Laisa, una travesti, y Emilio Uriarte, un hombre bisexual. Esta historia también adquirió mucha importancia en el relato total. La diferencia radica en que Emilio Uriarte parecía desconocer que su amada era travesti.

6. La zona del Delta se compone de un conjunto de islas, bastante próximas a la Ciudad de Buenos Aires. Debido a su topografía, algunas islas son menos accesibles que otras, lo que hace de este lugar un perfecto escondite.

7. Jugar al Teto es un chiste vulgar en el que el interlocutor pregunta cómo se juega, y quien lo propuso remata con "Agáchate y te la meto".

8. Fierro es una forma coloquial de llamar a las armas en algunas partes de Argentina

9. La muerte de Pedro se relacionaba con que el actor, Benjamín Vicuña, ya tenía previsto otros compromisos laborales para esa fecha, debido a que la telenovela había sido pensada para una miniserie. Los guionistas sostuvieron que era la mejor forma de darle salida a Pedro, más que un viaje o un nuevo amor

10. Chongazo deriva de chongo, forma habitual de llamar a los varones viriles y masculinos. En la jerga homosexual chongo, ligado al macho activo, se opone a loca, el pasivo afeminado (Sívori, 2005).

11. Del inglés, tea-room, tetera hace referencia a baños públicos en los que se tiene sexo casual con otro hombre. 


\section{REFERENCIAS}

Aguirre, C. (October 25, 2015). Sí, yo maté a Pedro [Yes, I killed Pedro]. La Nación. Retrieved from http://www.lanacion.com.ar/1839236-si-yo-mate-a-pedro

Aprea, G. \& Soto, M. (1998). Telenovela, telecomedia y estilo de época. El sistema de géneros narrativos audiovisuales en la Argentina hoy [Soap opera, telecommedy and epochal style. The audiovisual narrative genre system in nowadays Argentina]. Paper presented at the Asociación Latinoamericana de Investigadores de la Comunicación. Recife, Brasil.

Arnoux, E. (2008). El discurso latinoamericanista de Hugo Chávez [Latinoamericanist discourse of Hugo Chávez]. Buenos Aires, Argentina: Biblos.

Beck, U. \& Beck-Gernsheim, E. (2001). El normal caos del amor. Las nuevas formas de la relación amorosa [The normal chaos of love. New ways of amorous relationships]. Barcelona, Spain: Paidós.

Bericat, E. (2014). Matrimonio, desigualdad de género y bienestar socioemocional de los miembros de la pareja [Marriage, gender inequity and socio-emotional well-being of the partners of the couple]. In A. García Andrade \& O. Sabido Ramos (Coord.), Cuerpo y afectividad en la sociedad contemporánea [Body and affectivity in the contemporary society] (pp. 191-228). Mexico City, Mexico: Universidad Autónoma Metropolitana.

Butler, J. (1999). El género en disputa. El feminismo y la subversión de la identidad [Gender trouble. Feminism and the subversión of identity]. Barcelona, Spain: Paidós.

Cevasco, M. E. (2013). Diez lecciones sobre estudios culturales [Ten lessons on Cultural Studies]. Buenos Aires, Argentina: La Marca.

Connell, R. W. (2005). Masculinities. Los Angeles, USA: University of California Press.

Fassin, E. (2011). A Double-Edged Sword: Sexual Democracy, Gender Norms, and Racialized Rhetoric. In J. Butler \& E. Weed (Eds.), The Question of Gender. Joan W. Scott's Critical Feminism (pp. 143-158). Bloomington, USA: Indiana University Press.

Forster, E. M. (2003). Maurice. Madrid, Spain: Alianza Editorial.

Geertz, C. (2003). La interpretación de las culturas [The interpretation of cultures]. Barcelona, Spain: Gedisa.

Giddens, A. (2004). La transformación de la intimidad. Sexualidad, amor y erotismo en las sociedades modernas [The transformation of intimacy. Sexuality, love \& eroticism in modern societies]. Madrid, Spain: Cátedra.

Goffman, E. (2006). Estigma: la identidad deteriorada [Stigma. Notes on the management of spoiled identity]. Buenos Aires, Argentina: Amorrortu.

Gómez Rojas, G. (2007). ¿Cómo se constituyen las parejas? Entre las diversas formas del amor y los límites de la clase social [How are couples made? Between different forms of love and the limits of social class]. Revista Científica de UCES, 11(2), 68-75. Retrieved from http://dspace.uces.edu.ar:8180/ xmlui/handle/123456789/150

Grignon, C. \& Passeron, J. C. (1989). Lo culto y lo popular: miserabilismo y populismo en la sociología y en la literatura [The cult and the popular: miserabilism and populism in sociology and literature]. Buenos Aires, Argentina: Nueva Visión.

Hall, S. (2004). Codificación y descodificación en el discurso televisivo [Encoding and decoding in the television discourse]. CIC. Cuadernos de información y comunicación, 0(9), 215-236. Retrieved from https://revistas.ucm.es/index.php/CIYC/article/view/CIYC0404110215A

Hiller, R. (2012). En las faldas de O’Donnell: discutiendo los alcances del "matrimonio igualitario" en Argentina [On O'Donnell's slap: discussing about "egalitarian marriage" in Argentina]. Sociedade e Cultura, 15(2), 359-368. https://doi.org/10.5216/sec.v15i2.22403

Hiller, R. (2013). Notas sobre el matrimonio gay lésbico en Argentina: estudiar los procesos políticos en su contemporaneidad [Notes on gay-lesbian marriage in Argentina: studying political processes in their contemporarity]. Identidades, (0)0, 60-68. Retrieved from https://iidentidadess.files.wordpress. com/2013/08/hiller-pdf.pdf 
Illouz, E. (2009). El consumo de la utopía romántica. El amor y las contradicciones culturales del capitalismo [Consuming the romantic utopia. Love and the cultural contradictions of capitalism]. Buenos Aires, Argentina: Katz.

Illouz, E. (2012). ¿Por qué duele el amor? Una explicación sociológica [Why love hurts. A sociological explanation]. Buenos Aires, Argentina: Katz.

Jónasdóttir, A. G. (2014). Los estudios acerca del amor: un renovado campo de interés para el conocimiento [Love studies. A (re)new(ed) field of knowledge interests]. In A. García Andrade \& O. Sabido Ramos, (Coord.), Cuerpo y afectividad en la sociedad contemporánea [Body and affectivity in the contemporary society] (pp. 39-80). Mexico City, Mexico: Universidad Autónoma Metropolitana.

Jones, D. \& Hiller, R. (2015). Horizontes de la ciudadanía sexual de cara al cambio de ciclo [Horizons of sexual citizenship facing the turn of cycle]. Ciencias Sociales. Revista de la Facultad de Ciencias Sociales/UBA, 89, 102-107. Retrived from http://www.sociales.uba.ar/wp-content/blogs.dir/219/ files/2015/10/102-107-MODELOS.pdf

Le Breton, D. (1999). Las pasiones ordinarias. Antropología de las emociones [Ordinary passions. Anthropology of emotions]. Buenos Aires, Argentina: Nueva Visión.

Luhmann, N. (2008). El amor como pasión. La codificación de la intimidad [Love as passion. The codification of intimacy]. Barcelona, Spain: Península.

Mazziotti, N. (1993). Intertextualidades en la telenovela argentina. Melodrama y costumbrismo [Intertextuality in argentinean soap opera. Melodrama and costumbrismo]. In N. Mazziotti (Comp.), El espectáculo de la pasión. Las telenovelas latinoamericanas [The spectacle of passion. Latin American telenovelas] (pp. 156-164). Buenos Aires, Argentina: Colihue.

McRobbie, A. (1998). More! Nuevas sexualidades en las revistas para chicas y mujeres [More! New sexualities in girls and women's magazines]. In J. Curran, D. Morley \& V. Walkerdine (Comps.), Estudios culturales y comunicación: análisis, producción y consumo cultural de las políticas de identidad y el posmodernismo [Cultural Studies and Communication: analysis, production and cultural consumption of identity politics and postmodernism] (pp. 263-295). Barcelona, Spain: Paidós.

McRobbie, A. (2010). ¿Las chicas arriba? Las mujeres jóvenes y el contrato sexual posfeminista [Top girls? Young women and the post-feminist sexual contract]. Debate Feminista, 41, 113-135. Retrieved from http://www.jstor.org/stable/42625139?seq=1\#page_scan_tab_contents

Meccia, E. (2006). La cuestión gay. Un enfoque sociológico [The gay question. A sociological approach] Buenos Aires, Argentina: Gran Aldea Editores.

Meccia, E. (2011). Los últimos homosexuales. Sociología de la homosexualidad y la gaycidad [Last homosexuals. Sociology of homosexuality and gayness]. Buenos Aires, Argentina: Gran Aldea Editores.

Melo, A. (2005). El amor de los muchachos. Homosexualidad \& Literatura [Young boys loving. Homosexuality \& literature]. Buenos Aires, Argentina: Ediciones Lea.

Ortega, S. \& Cullel, P. (Productores). (2014-2015). Viudas e hijos del rock and roll [TV serie]. Buenos Aires: Telefé.

Paiva, V. (2006). Analisando cenas e sexualidades: a promocao da saúde na perspectiva dos direitos humanos [Analyzing scenes and sexuality: a health intervention-study using a human rights-based approach]. In C. Cáceres et al. (Eds.), Sexualidad, estigma y derechos humanos: desafíos para el acceso a la salud en América Latina [Sexuality, stigma and human rights: challenges for accessing health in Latin America] (pp. 23-51). Lima, Peru: FASPA/UPCH.

Pecheny, M. (2003). Identidades discretas [Discrete identities]. In L. Arfuch (Comp.), Identidades, sujetos y subjetividades [Identities, subjects and subjectivities] (pp. 125-147). Buenos Aires, Argentina: Prometeo.

Pecheny, M. (2008). Introducción. Investigar sobre sujetos sexuales [Introduction. Researching about sexual subjects]. In M. Pecheny, C. Fígari \& D. Jones (Comps.), Todo sexo es político: estudios sobre sexualidad en Argentina [All sex is political: studies on sexuality in Argentina] (pp. 9-17). Buenos Aires, Argentina: Libros del Zorzal. 
Restrepo, E. (2012). Antropología y estudios culturales. Disputas y confluencias desde la periferia [Anthropology and cultural studies. Disputes and confluences from periphery]. Buenos Aires, Argentina: Siglo XXI.

Sívori. H. (2005). Locas, chongos y gays. Sociabilidad homosexual masculina durante la década de 1990 [Queer, chongos and gays. Masculine homosexual sociability during the 90s]. Buenos Aires, Argentina: Antropofagia.

Sousa Dias, G. (September 08, 2013). Cambio social. Avanza en el país la aceptación al amor gay [Social change. The acceptance of gay love advances in the country]. Clarin. Retrieved from http://www. clarin.com/sociedad/Cambiosocial-Avanza-aceptacionamor_0_989301156.html

Sullivan, A. (1996). Virtually normal: an argument about homosexuality. New York, USA: Vintage Books.

Thompson, E. P. (1995). Costumbres en común [Customs in common]. Barcelona, Spain: Crítica.

Weitman, S. (1999). On the Elementary Forms of the Socioerotic Life. In M. Featherstone (Ed), Love $\varepsilon$ Eroticism (pp. 71-110). London: UK: Sage.

Williams, R. (1982). Cultura y Sociedad 1780-1950. De Coleridge a Orwell [Cutlure and society, 1780-1950. From Coleridge to Orwell]. Buenos Aires, Argentina: Nueva Visión.

Williams, R. (2009). Marxismo y literatura [Marxism and literature]. Buenos Aires, Argentina: Las Cuarenta.

Wood, J. T. (1994). Gendered Lives: Communication, Gender, and Culture (pp. 231-244). Belmont, CA: Wadsworth Publications.

\section{SOBRE EL AUTOR}

Maximiliano Marentes, realiza el doctorado en Ciencias Sociales en la Universidad de Buenos Aires. Licenciado en Sociología por la Universidad Nacional de General San Martín. Becario doctoral del Consejo Nacional de Investigaciones Científicas y Técnicas. Investiga sobre amor en varones gays desde una perspectiva sociológica. Ha participado en investigaciones sobre clases altas, protesta social, movilización de familiares de víctimas y situaciones de espera. 